\title{
Saturation and the Limit of Jet Mixing Enhancement by Single Frequency Plane Wave Excitation: Experiment and Theory
}

Ganesh Raman

Sverdrup Technology, Inc.

(Lewis Research Center Group)

NASA Lewis Research Center

Cleveland, Ohio

Edward J. Rice

NASA Lewis Research Center

Cleveland, Ohio

\section{Lieratiri birt}

and

Reda R. Mankbadi

Brown University

SEP 281988

LANGLEY RESEARCH CENTER - maUPTON. VIRGINIA

Providence, Rhode Island

Prepared for the

First National Fluid Dynamics Congress

cosponsored by the AIAA, ASME, ASCE, SIAM, and APS

Cincinnati, Ohio, July 24-28, 1988

\section{N/Sก}


$$
\text { • }
$$$$
\text { - }
$$

$+$ 
PLANE WAVE EXCITATION: EXPERIMENT AND THEORY

\author{
Ganesh Raman \\ Sverdrup Technology, Inc. \\ (Lewis Research Center Group) \\ NASA Lewts Research Center \\ Cleveland, Ohio 44135 \\ Edward J. Rice \\ NASA Lewis Research Center \\ Cleveland, Ohio 44135 \\ and \\ Reda R. Mankbadi* \\ Division of Engineering and Laboratory for \\ Fluid Mechanics, Turbulence, and Computation \\ Brown University \\ Providence, Rhode Island 02912
}

\section{Abstract}

The limitations of single frequency plane wave excitation in mixing enhancement are investigated for a circular jet. Measurements made in an $8.8 \mathrm{~cm}$ diameter jet are compared with a theoretical model. The measurements are made to quantify mixing at excitation amplitudes up to 2 percent of the jet exit velocity. The initial boundary layer state, the exit mean and fluctuating velocity profiles and spectra are documented for all cases considered. The amplitude of the fundamental wave is recorded along the jet axis for various levels of excitation. As the amplitude of excitation is increased the jet spreading rate is increased, but beyond a "saturation" amplitude, further increases have no effect on the spreading. The experimental results are compared with theoretical estimates. In the theory the flow is split into the mean flow, large scale motions, and fine scale turbulence. Shape assumptions for the mean flow, and fine scale turbulence along with the shape for the large scale motions obtained from a linear stability theory provide the closure. The experimental results compare reasonably well with the predictions.

\section{Introduction}

Enhanced mixing of jets by artificlal excitation has been the focus of numerous investigations. $1-3$ These parametric investigations provided information about the effect of factors such as excitation Strouhal number, amplitude and mode of excltation, Reynolds number, and the nature of the boundary layer at the nozzle exit. In some studies $3-5$ the value of the ratio of mean velocity with excitation to that without excitation at $x / D=9$ on the jet centerline was used as a measure of jet mixing enhancement. The maximum achievable value of this ratio is about $U(e x) / U($ unex $)=0.8$, using single frequency plane wave excitation. It was assumed that the levels of excitation were insufficient to enhance mixing further and that designing a device to produce higher levels would help bring these values down further.

*On leave from the Department of Mechanical Engineering, Cairo University, Cairo, Egypt.
This study focusses on some inherent limitations of single frequency excitation in the plane wave mode. Measurements were made using the axisymmetric jet facility at NASA Lewis Research Center, at Mach numbers ranging from 0.15 to 0.54 and excitation levels

$$
\left(\frac{u_{f o}^{\prime}}{u_{j}}\right)
$$

from 0.05 to 2 percent of the jet velocity. Most of the measurements were made at a Mach number of 0.2 . The results are compared with the predictlons of a theoretical model which was developed by Mankbadi and Liu6,7 at Brown University. This theoretical model considers the role of forcing on the growth of the shear layer. The model permits the study of the relative dominance of mehanisms such as entrainment due to the growth of large scale coherent structures and entrainment due to enhanced intensity of fine grained turbulence.

\section{Experimental Apparatus and Procedure}

The jet facility shown in Fig. I contains a $76 \mathrm{~cm}$ diameter plenum chamber supplied with pressurized air. The flow passes through three screens and two stages of contraction before exiting through the $8.8 \mathrm{~cm}$ diameter nozzle. A $20.3 \mathrm{~cm}$ butterfly valve bypassed by a $3.8 \mathrm{~cm}$ Annin plug valve, both operated remotely are used to control the flow. A $41 \mathrm{~cm}$ diameter section located between the two contracting sections contains the excitation system which consists of four acoustic drivers that are equally spaced about the circumference. Each driver is enclosed in a sealed can and vented to equalize pressure across the driver dlaphragm. Figure 1 is a photograph of the jet facility and probe traversing mechanism. A schematic showing the nozzle and the exitation system is provided in Ref. 5. A Rockland Scientific Variphase tone generator provides the exciation signal. This signal is amplified by Altec Lansing power amplifiers and fed to the acoustic drivers.

A specially fabricated boundary layer trip ring is located $33 \mathrm{~cm}$ upstream of the nozzle exit where the diameter of the contracting section is $13.1 \mathrm{~cm}$; the nozzle ended with a sharp edge and has a $22 \mathrm{~cm}$ long cylindrical section prior to the 
exit. The trip ring has 82 saw-teeth which protrude $4.76 \mathrm{~mm}$ into the flow.

Measurements of mean and fluctuating velocity were made with hot-wire anemometers. The coherent motions were extracted by the phase averaging technique. The phase average is the average of data points having the same phase with respect to a reference signal. The phase averaging rejects the background turbulence and educts the underlying, periodic, coherent component. The phase average measurements and spectrum analysis were done using a B\&K dual channel signal analyzer. A computer controlled traversing mechanism was used for probe positioning.

\section{Theoretical Considerations}

The theory of Mankbadl and Liu (Refs. 6 and 7) includes the effect of excitation on shear layer growth and accounts for interactions between the mean flow, large scale structures, and fine scale turbulence, in a round jet. The problem is approached by splitting the total flow into the time averaged mean, and a coherent component at an idealli_ed single frequency, the rest being lumped as the "incoherent" component. The kinetic energy equations are written and brought to a radialiy integrated form. The closure is addressed by making shape assumptions for the mean flow and the fine scale turbulence. For the mean flow radial shape the theory uses a two-stage hyperbolic tangent proflle. such as the one proposed by Michalke.8 The profile shape for the coherent component is obtained from predictions of locally parallel stability analysis, e.g. that of Michalke.8 The final product is a set of three nonlinear ordinary differentlal equations, which can be solved to obtain the momentum thickness, fine scale turbulence energy flux and the large scale structure amplitude as a function of axial distance. A detalied description of the theoretical development is provided in Refs. 6 and 7.

\section{Results and Discussion}

As the initial conditions play a very significant role in the development of the shear layer, these conditions were carefully documented.

Figure 2 shows the longltudinal mean velocity (U) and turbulence intensity ( $\left.u^{\prime}\right)$ profiles at the nozzle exit plane normalized by the jet exit velocity $\left.U_{f}\right)$. The mean velocity proflles are top-hat in shape, with a very small momentum thickness at the nozzle exit. The turbulence measured in the boundary layer at positive values of $r$ is higher because the probe and its support mechanism were positioned within the jet flow in order to reach this slde. This flow impingement resulted in small probe vibrations which were sufficlent to contaminate the data in the thin boundary layer. All subsequent measurements are on the axis or in the boundary layer on the negative $r$ side where only the probe and the stem entered the flow causing minimal vibrations. Velocity spectra measured within the nozzle exit boundary layer and on the jet centerline are shown in Fig. 3. The boundary layer spectrum shown was measured at the radial location where the maximum velocity fluctuations occurred. Neither spectra show any distinct peaks. This indicates that the flow is reasonably "clean" and free of tones from valve and flow noise. The exit boundary layer spectrum also shows that there are no remnants of organized shedding from the tripping device that is located upstream. Shape factor, momentum thickness and peak fluctuation level measured about $0.5 \mathrm{~mm}$ downstream of the nozzle lip are shown in Fig. 4. The boundary layer characteristics are essentially the same in the Mach number range 0.1 to 0.35 . Based on the se characteristics the boundary layer could be considered as "nominaliy turbulent." The exit conditions were thus "tallored" using the boundary layer tripping device described in an earlier section and more thoroughly in Ref. 5 .

\section{$\frac{\text { Measurements to Quantify the Spreading Rate }}{\text { of the Jet }}$}

The decay of mean velocity along the jet axis for various levels of excitation is shown in Fig. 5. The mean velocity normalized by the jet exit velocity is plotted versus a dimensionless axial distance for a case where the Mach number was 0.2 . Excitation was at a Strouhal number, $\left(f D / U_{e}\right)$, of 0.5 and the excltation level was varied from zero to 2 percent of the exit velocity. It is seen that with increase in the level of excitation, the jet decays more rapidly, but beyond a level of excitation of about 0.875 percent no further effect on the jet decay is observed. The jet decay rate is therefore found to be saturated. The jet centerline turbulence intensity plotted versus dimensionless axial distance is shown in Fig. 6. The turbulence, in this case, is a sum of the coherent and incoherent contributions. All conditions are the same as in Fig. 5. As in the mean velocity data the effect of increased excitation on the turbulence diminishes beyond the certain level of excitation. A plot of $U(e x) / U($ une $x$ ) measured on the jet centerline, at $x / D=9$, versus the level of excitation measured at the jet exit is shown in Fig. 7. A lower value of mean velocIty at $x / D=9$ indicates higher spreading rates. Figure 7 shows that the ratio of $U(e x) / U($ unex) drops quickly to a value near 0.8 at excitation levels as low as 0.3 percent but a further increase in the excitation level does not reduce this ratio any further.

As the mean centerline velocity measurements at $x / D=9$ are not a direct measure of the jet spreading rate, the jet spreading as represented by the shear layer momentum thickness was measured at $x / 0=9$. This is shown in Fig. 8. Momentum thickness (excited)/momentum thickness (unexcited) is plotted versus the excitation level. The momentum thickness used here is defined as,

$$
\int_{0}^{\infty} \frac{U}{U_{c}}\left(1-\frac{U}{U_{c}}\right) d r \text {. }
$$

where $U_{c}$ is the local centerline mean velocity. The data in this figure also exhibits the "saturation" seen in the earlier figures. The knee of the curve is at a level of 0.3 percent of the jet exit velocity, which is the same conclusion drawn from the mean centerline velocity measurements shown in Fig. 7 .

Figure 9 shows the normalized peak amplitude of the fundamental wave as measured along the jet axis for various levels of excitation. As the excitation levels are increased the peak level attained by the fundamental wave gets higher and eventually saturates. Also obvious from the figure is a clear upstream shift in the location of this peak with increasing initial excitation 
level. The peak level of the fundamental can be viewed as another indication of jet spread, since as the fundamental wave grows it extracts energy from the mean flow thus causing the jet to spread at a faster rate. The peak amplitude attained by the fundamental wave is plotted versus the level of excitation in Fig. 10. This is seen to saturate at the same level of excitation at which the spreading rate and mean velocity at $x / D=9$ are seen to saturate. This implies that the process of mixing enhancement in this experiment is dominated by the growth of the fundamental wave.

The growth and decay of the fundamental, the subharmonic, harmonic and the total fluctuation, measured along the nozzle axis, are shown in Fig. 11. The jet spreading rate is essentially governed by the fundamental and the development of fine scale turbulence in the jet. In Fig. 11 the fundamental is obtained by phase averaging whereas the subharmonic and harmonic are obtained by filtering and the total turbulence is the energy content of the entire spectrum. The harmonic cannot be defined in the axial region where it decays because the background turbulence levels get higher than the harmonic at around $x / d=3$.

Most of the data discussed so far has been at a Mach number of 0.2 . Data is shown in Fig. 12 for $M=0.2,0.3$ and 0.54 . $U(e x) / U($ unex) measured at $x / D=9$ on the jet centerline is plotted versus the level of excitation. Saturation is seen at Mach numbers of 0.2 and 0.3 . At a Mach number of 0.54 the "saturation" level could not be reached. This was because the excltation system could not produce levels as high as 0.3 percent of the exit velocity corresponding to $M=0.54$. Therefore it seems that efforts to control high Mach number jets would experience a simllar "saturation limit" when devices to produce such levels are developed. Jet mixing control using single frequency plane wave excitation appears to be quite limited. It is possible that other modes of excitation, however, would overcome this restriction.

\section{Experiment Versus Theory}

Theoretical estimates based on the Mankbadi and Liu theory are compared with the experimental data in Flgs. 13 and 14 . The solution of the system of equations representing the development of each flow component requires the exit momentum thickness, the inltial excitation level and the turbulence energy at the jet exit. Measured values of these quantities from the experiment are input as initial conditions for the computations. The exit momentum thickness $(\theta / D)$ was measured to be 0.006 . The initlal turbulence energy was calculated by integration of the measured turbulence profile at the exit

$$
E=\int_{0}^{\infty} u^{2} r d r
$$

$E=0.0001$ was used and the inftial excitation level was varled as in the experiment.

The maximum coherent velocity component at the excitation signal fundamental frequency as found along the jet axis as a function of the excitation level is shown in Fig. 13 (data same as in Fig. 10). The figures show that at low excitation levels the theory underestimates the coherent com- ponent. However, the figure shows that the theory indicates the same saturation behaviour as in the experiment. The maximum coherent velocity component that can be reached along the jet is about 8 percent of the jet exit velocity. The saturation behaviour can be explained using the theory as follows. The coherent component grows by extracting energy from the mean flow. This mean flow production of the coherent component is proportional to the energy of the coherent component and is inversely proportional to the momentum thickness of the mean flow. Thus, an initially high level of the coherent structure energy will result in a rapid absorption of energy from the mean flow. However, this also results in a rapid growth of the mean flow momentum thickness and therefore less energy is available for the subsequent development of the coherent component. Thus, the coherent structure "chokes" from its own energy. Thus, further increase in the excitation level can not result in amplification of the coherent component and a saturation limit is reached.

The ratio of the jet's momentum thickness at $x / d=9$ for the excited and the unexcited conditions is shown in Fig. 14 versus the excitation level. At low excitation levels, the theory predicts the same values as in the experiment. At higher excitation levels the theory underestimates the effect of excitation on the momentum thickness. The present theory only considers a single frequency component of the coherent structure. However, if the energy of the fundamental component of the coherent structure is relatively high, a subharmonic of the fundamental can be amplified as in Refs. II and 12 and as observed in this experiment and shown in figure 11. This subharmonic also absorbs energy from the mean flow and results in further increases of the momentum thickness as studied by Mankbadi. 13 This could explain why at high excitation levels the single frequency theory underestimates the development of the jet.

\section{Flow Visualization}

Schlieren photographs taken from Ref. 3 are shown in Fig. 15. These pictures show the effect of increasing excitation levels on the jet structure at a Strouhal number of 0.5 . With increasing amplitude (indicated by the voltage input to the speaker). The effect of excitation on the jet structure is pronounced in the first three pictures. But little change occurred in the fourth picture in comparison to the third. A direct comparison with the present experiment can not be made as the excitation level in the visualization study is indicated by the voltages to the acoustic drivers. Values of the excitation level as a percent of the jet exit velocity are not avallable in Ref. 3. In a private communication with the principal author of Ref. 3 the possibility of the output from the acoustic drivers having reached saturation was discussed. When the voltage input to the drivers was increased from 10 to $40 \mathrm{~V}$ the output from the drivers did saturate, but the exact voltage where this occurred is not known. Though qualitative, these are indications that there exists an upper limit to which the structure shown in Fig. 15 can be altered by single frequency plane wave excitation. 


\section{Concluding Remarks}

1. There are limitations in jet mixing enhancement using single frequency plane wave excitation. Therefore the use of devices which provide higher levels of single frequency excitation may not yield better jet mixing or plume reduction.

2. This saturation is observed in all measured quantities of the jet evolution, 1.e. the fundamental wave amplitude, the momentum thickness and the centerline mean velocity and turbulence intensity. The level of excitation at which saturation of the fundamental wave is reached is the same as that at which the saturation of the increase in momentum thickness and the centerline mean velocity is reached. This level, for the presently studied jet at $M=0.2$, was found to be about 0.3 percent of the jet velocity.

3. The theory of Mankabadi and Liu can reasonably simulate the effect of excitation on the development of the jet. Inclusion of a mechanism by which subharmonics can be amplifled must be considered at high excitation levels.

4. More effective methods for flow control such as simultaneous excitation of the fundamental and subharmonic waves 9,10 or spinning mode excitation need to be parametrically studled in order to obtain further increases in jet mixing enhancement.

\section{Acknowledgements}

RRM was supported partially by DARPA/ACMP through its University Research Initiative, by NASA Lewis Research Center through Grant NAG3-673 and by NSF/FDHP through Grant MSM-8320307 at Brown University.

\section{References}

1. Crow, S.C., and Champagne, F.H., "Orderly Structure in Jet Turbulence," Journal of Fluid Mechanics Vol. 48, Pt. 3, Aug. 16, 1971, pp. 547-591.

2. Hussain, A.K.M.F., and Zaman, K.B.M.Q., "The 'Preferred Mode' of the Axisymmetric Jet," Journal of Fluid Mechanics, Vol. 110, Sept. 1981. pp. 39-71.

3. Ahuja, K.K., Lepicovsky, J., Tam, C.K.W. , Morris, P.J., and Burrln, R.H., "Tone Excited Jets: Theory and Experiments," NASA CR-3538, 1982.
4. Ahuja, K.K., Lepicovsky, J., and Brown, W.H., "Some Unresolved Questions on Hot-Jet Mixing Control Through Artificial Excitation," AIAA Paper 86-1956, July 1986.

5. Raman, G., Zaman, K.B.M.Q., and Rice, E.J., "Initial Turbulence Effect on Jet Evolution, With and without Tonal Excltation," AIAA Paper 87-2725, Oct. 1987. (NASA TM-100178)

6. Mankbadi, R., and Liu, J.T.C., "A Study of the Interactions Between Large-Scale Coherent Structures and Fine Grained Turbulence in a Round Jet," Philosophical Transactions of the Royal Society of London, Series A, Vol. 298A, No. 1443, Jan. 21, 1981, pp. 541-602.

7. Mankbadi, R.R., "On the Organized LargeScale Structure in a Turbulent Round Jet and Its Far-Field Sound," Ph.D. Thesis, Brown University, Providence, RI, 1979.

8. Michalke, A., "Survey on Jet Instability Theory," Progress in Aerospace Sciences. Vol. 21, No. 3, 1984, pp. 159-199.

9. Ho, C.M., and Huang, L.S., "Subharmonics and Vortex Merging in Mixing," Journal of Fluid Mechanics, Vol. 119, June, 1982, pp.443-473.

10. Mankbadi, R.R., "The Effect of PhaseDifference on the Spreading rate of a Jet," AIAA Journal, Vol. 24, No. 12, Dec. 1986, pp. 1941-1948

11. Zaman, K.B.M.Q., and Hussain, A.K.M.F. "Vortex Pairing in a Circular Jet Under Controlled Excitation, I-General Jet Response," Journal of Fluid Mechanics, Vol. 101, Pt. 3, Dec. 11.1980, pp. 449-491.

12. Mankbadi, R.R., "On the Interaction Between Fundamental and Subharmonic Instablilty Waves in a Turbulent Round Jet," Journal of Fluid Mechanics, Vol. 160, Nov. 1985, pp. 385-419.

13. Mankbadi, R.R., "The Mechanism of Mixing Enhancement and Supression in a Circular Jet Under Excitation Conditions," Physics of Fluids, Vol. 28, No. 7, July 1985, pp. 2062-2074. 


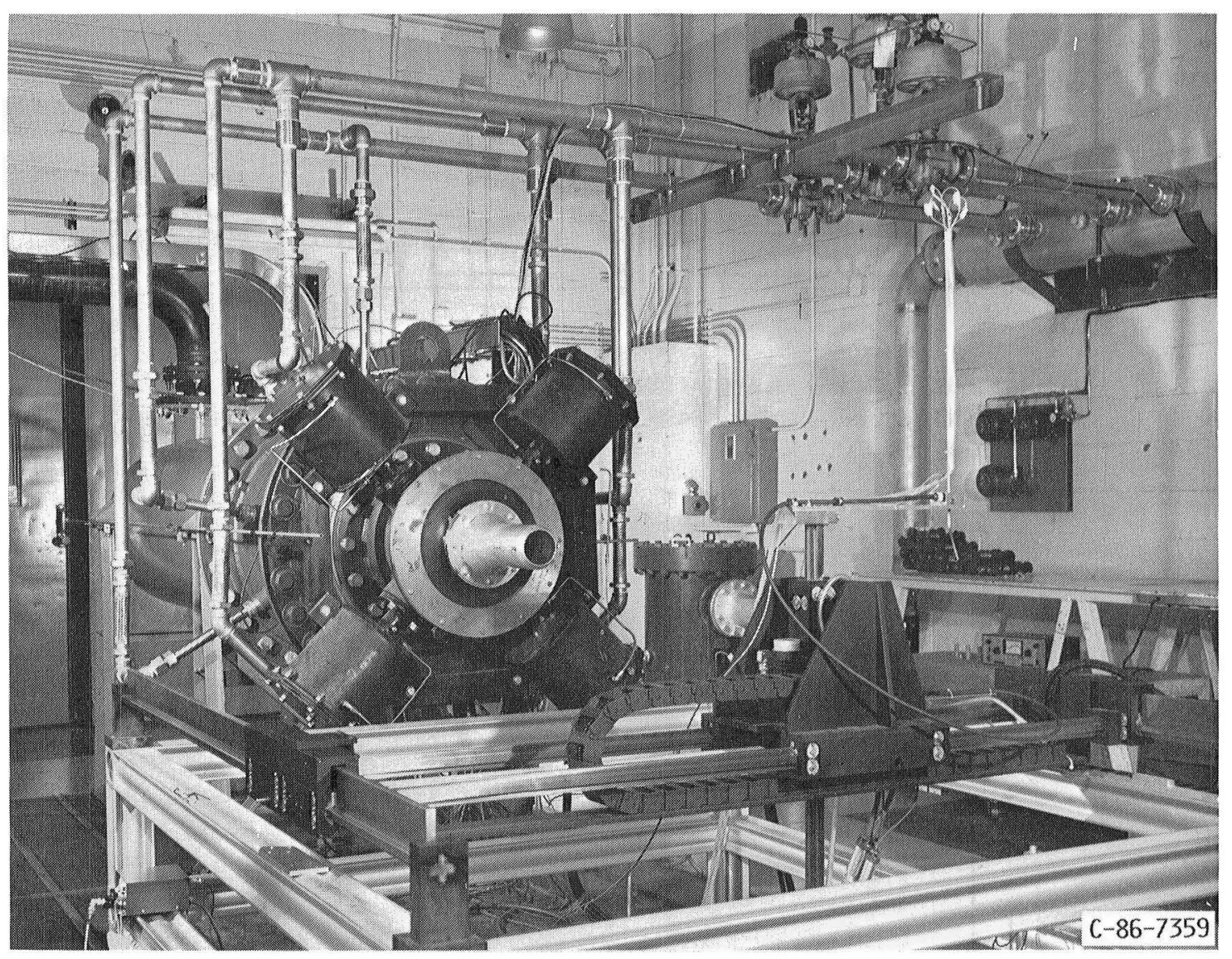

FIGURE 1. - JET FACILITY AND TRAVERSING MECHANISM. 


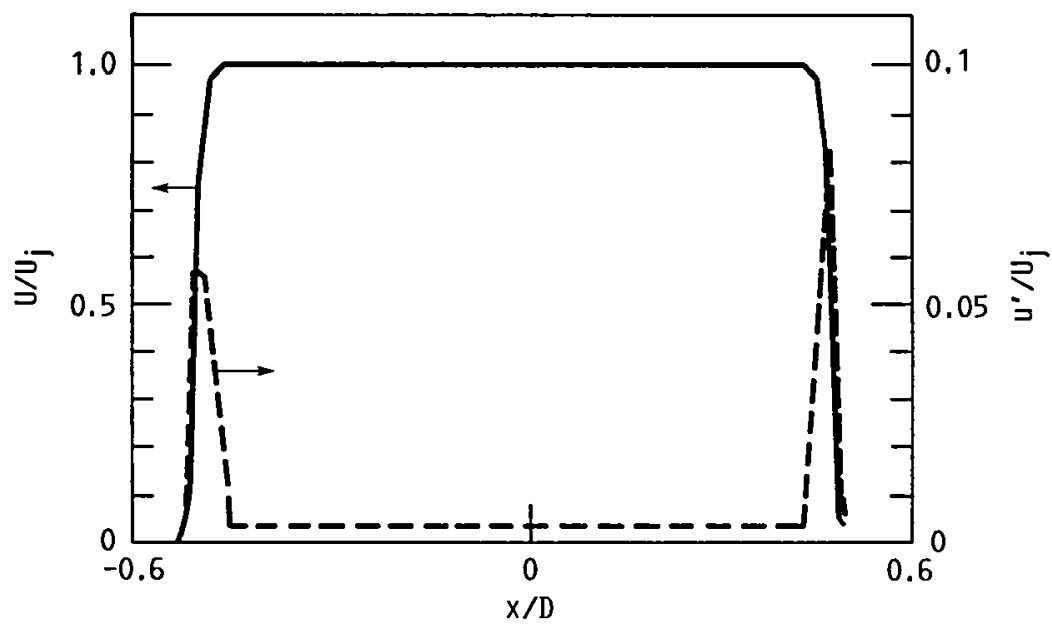

FIGURE 2. - RADIAL VARIATION OF MEAN (U, SOLID LINE)

AND FLUCTUATING ( $U^{\prime}$, DASHED LINE) VELOCITIES AT

THE JET EXIT.

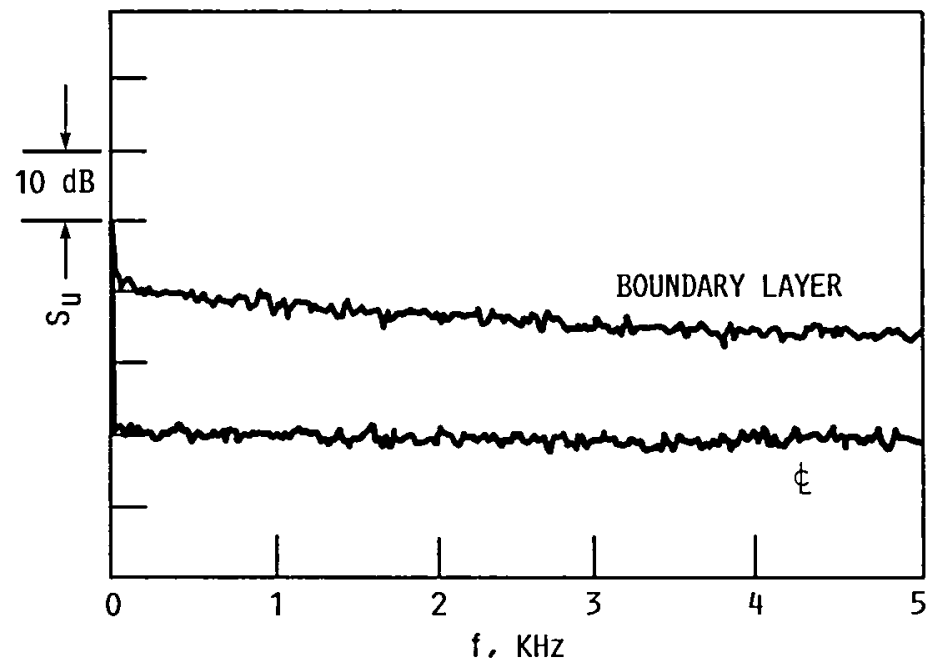

FIGURE 3. - $u^{\prime}$-SPECTRA MEASURED AT THE JET EXIT BOUNDARY LAYER AND CENTERLINE $(\notin)$; BANDWIDTH $12.5 \mathrm{~Hz}$. 


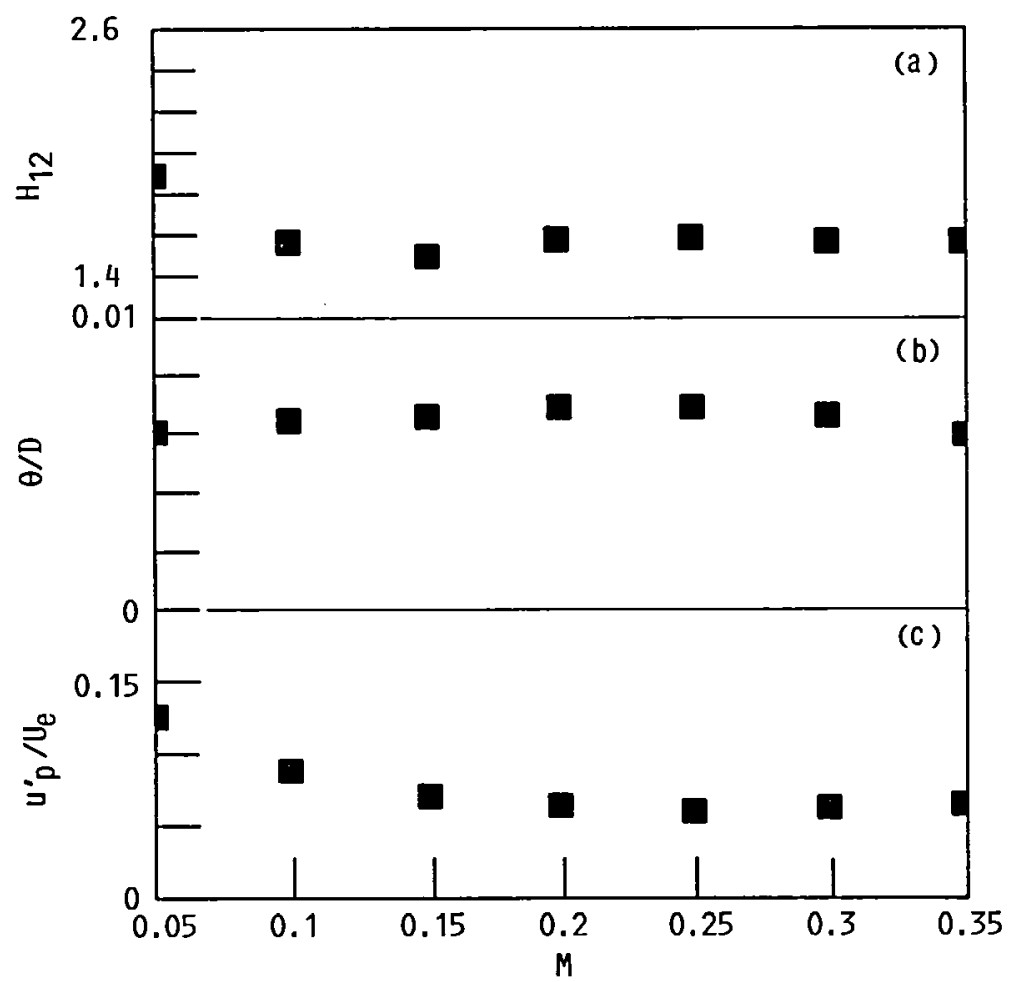

FIGURE 4. - BOUNDARY LAYER CHARACTERISTICS MEASURED 0.5 MM DOWNSTREAM OF THE JET EXIT.

(a) SHAPE FACTOR.

(b) MOMENTUM THICKNESS.

(c) PEAK FLUCTUATION INTENSITY. 


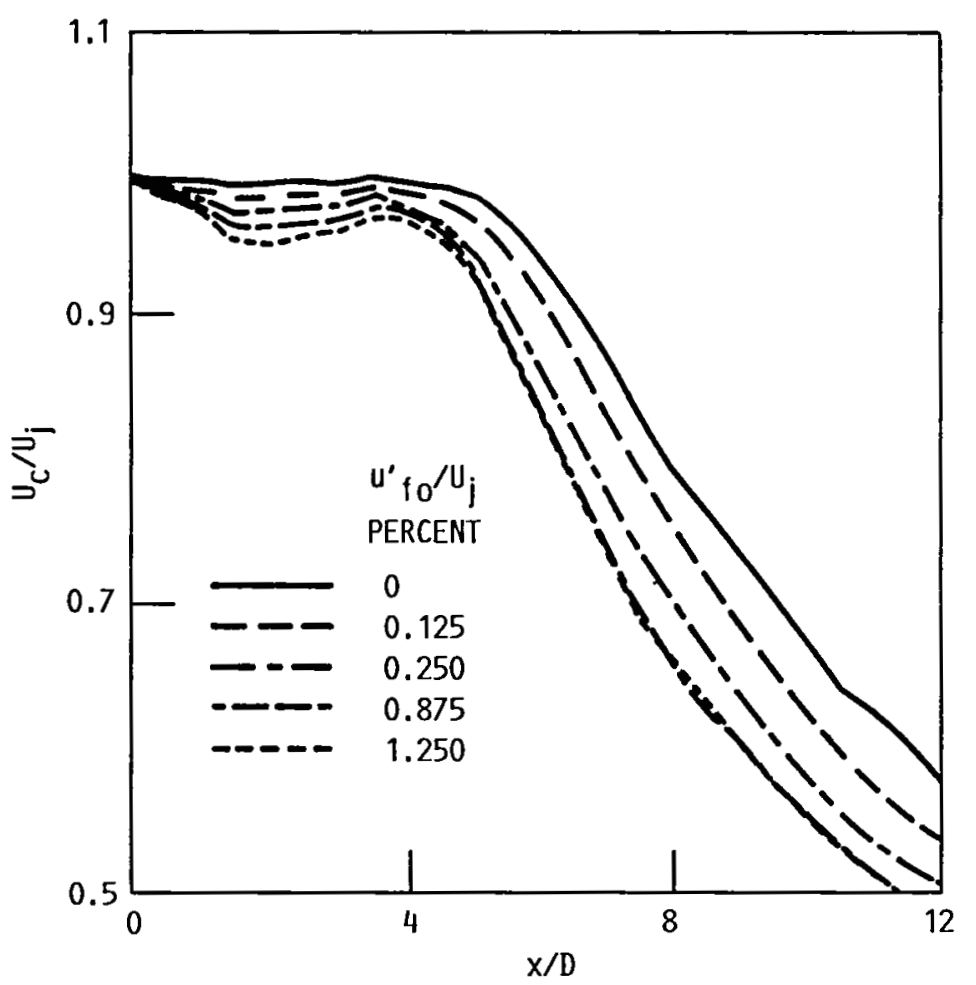

FIGURE 5. - CHARACTERISTIC DECAY OF MEAN VELOCITY ALONG THE CENTERLINE FOR VARIOUS LEVELS OF INITIAL EXCITATION, $(S t=0.5)$.

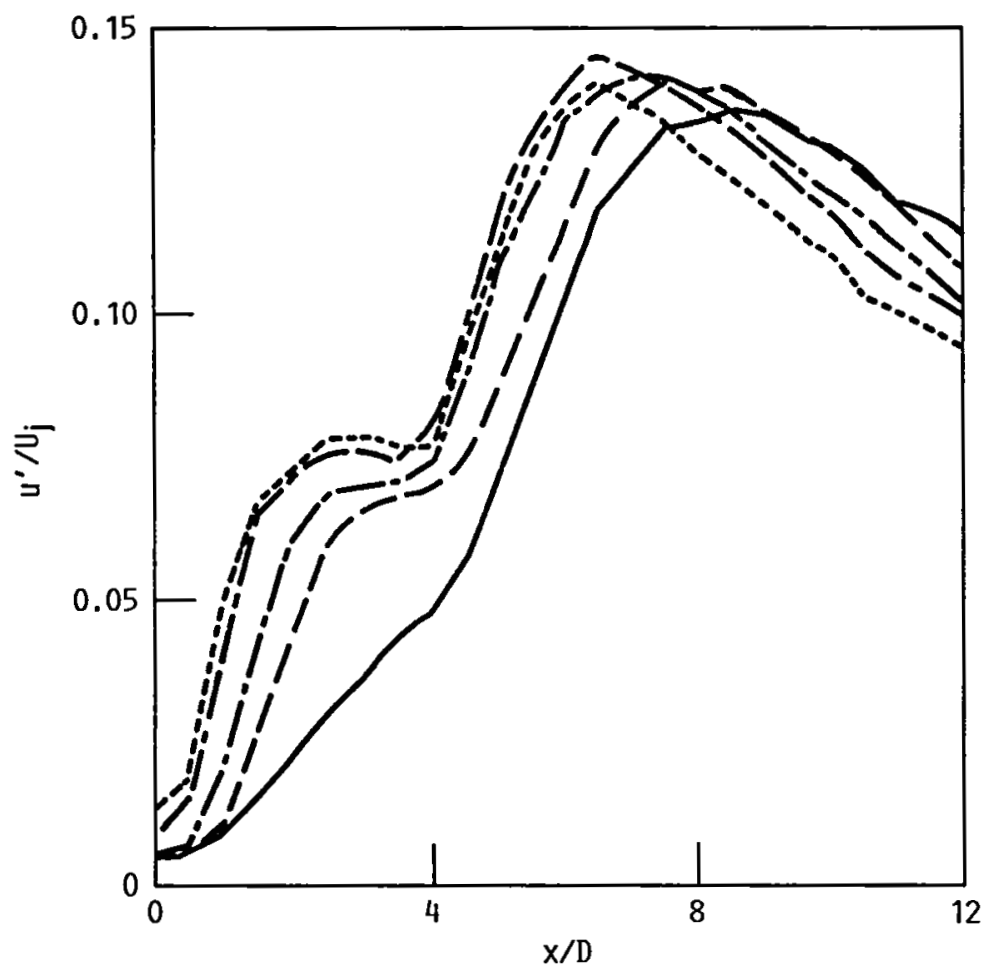

FIGURE 6. - CHARACTERISTIC DEVELOPMENT OF TURBULENCE INTENSITY ALONG THE CENTERLINE FOR VARIOUS LEVELS OF EXCITATION, $(S=0.5)$. SAME LINE CODES AS IN FIGURE 5. 


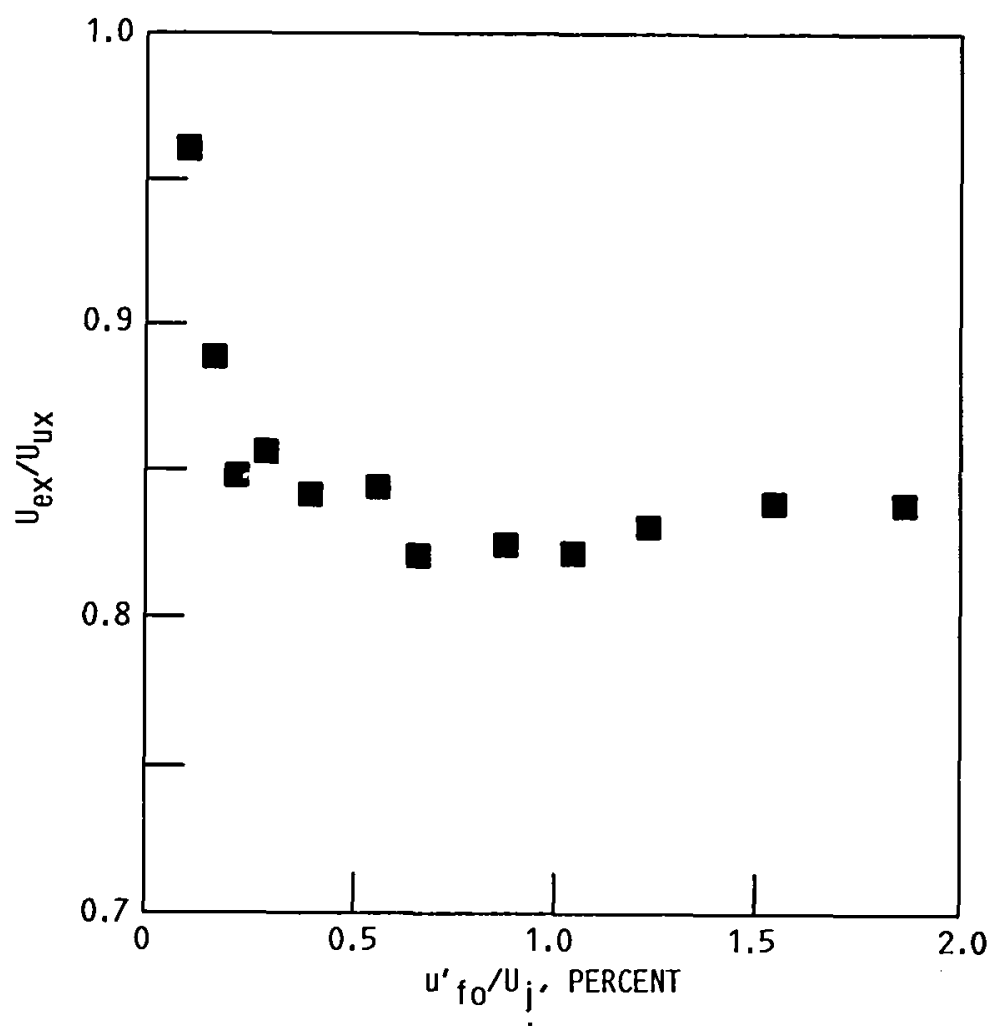

FIGURE 7. - VARIATION OF MEAN VELOCITY RATIO AT $X / D=9$ ON THE JET CENTERLINE WITH INITIAL LEVEL OF EXCITATION, $(S t=0.5, M=0.2)$,

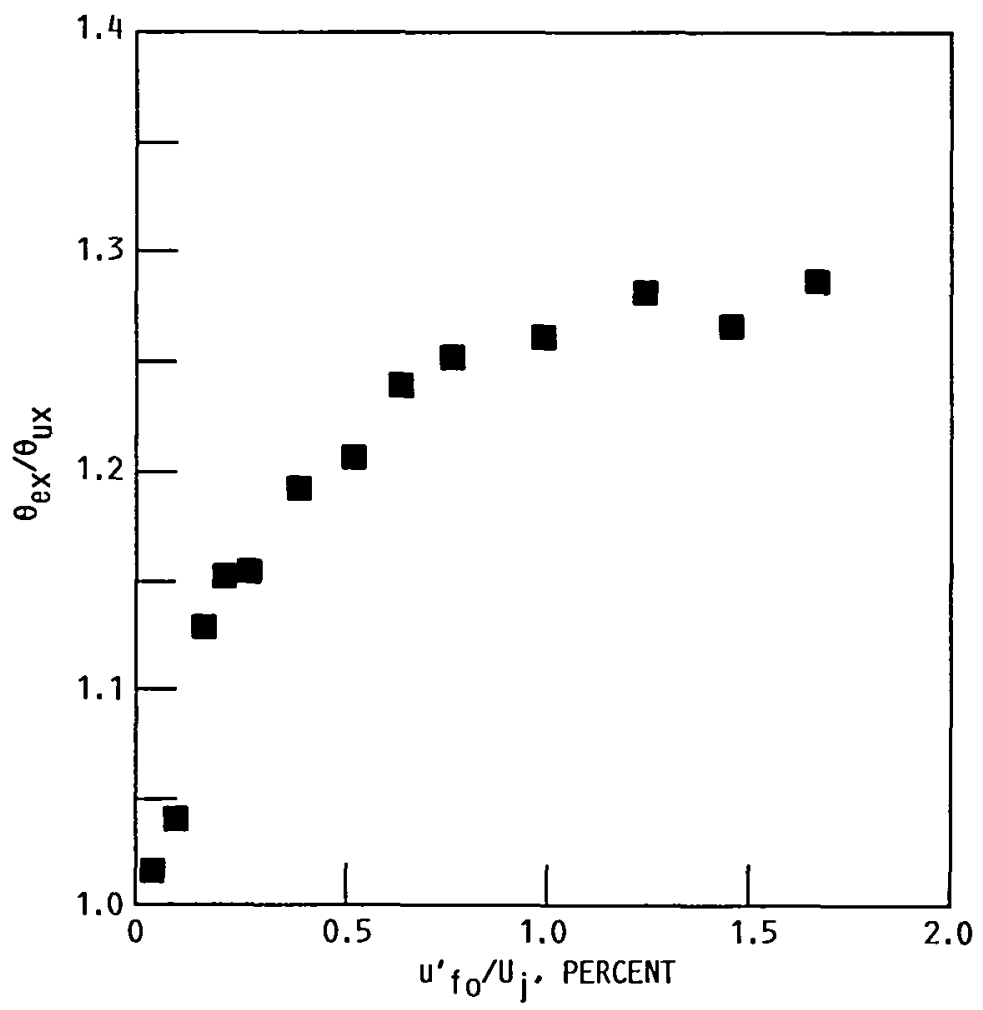

FIGURE 8. - VARIATION OF MOMENTUM THICKNESS (MEASURED AT $X / D=9$ ) WITH THE INITIAL LEVEL OF EXCITATION, $(S t=0.5, M=0.2)$. 


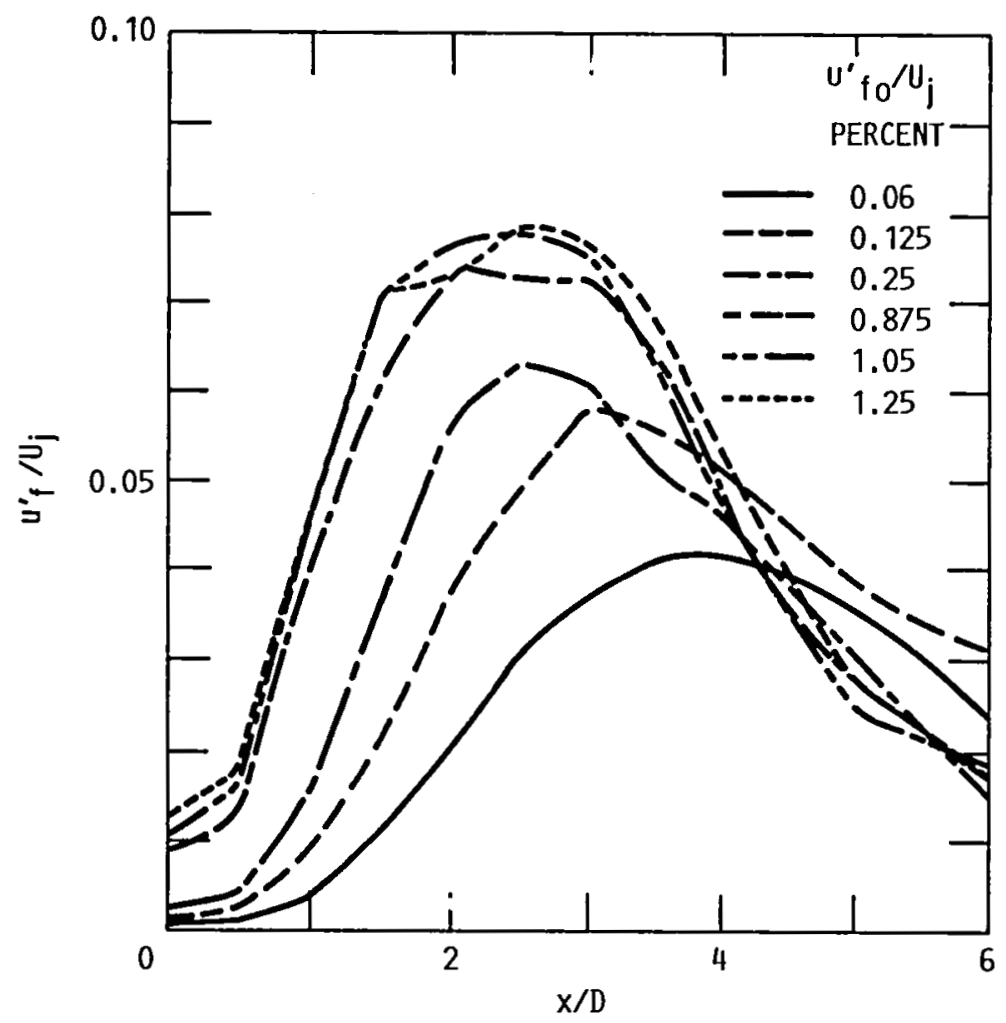

FIGURE 9. - GROWTH OF THE FUNDAMENTAL WAVE ALONG THE JET CENTERLINE FOR VARIOUS LEVELS OF INITIAL EXCITATION, $(S t=0.5, M=0.2)$.

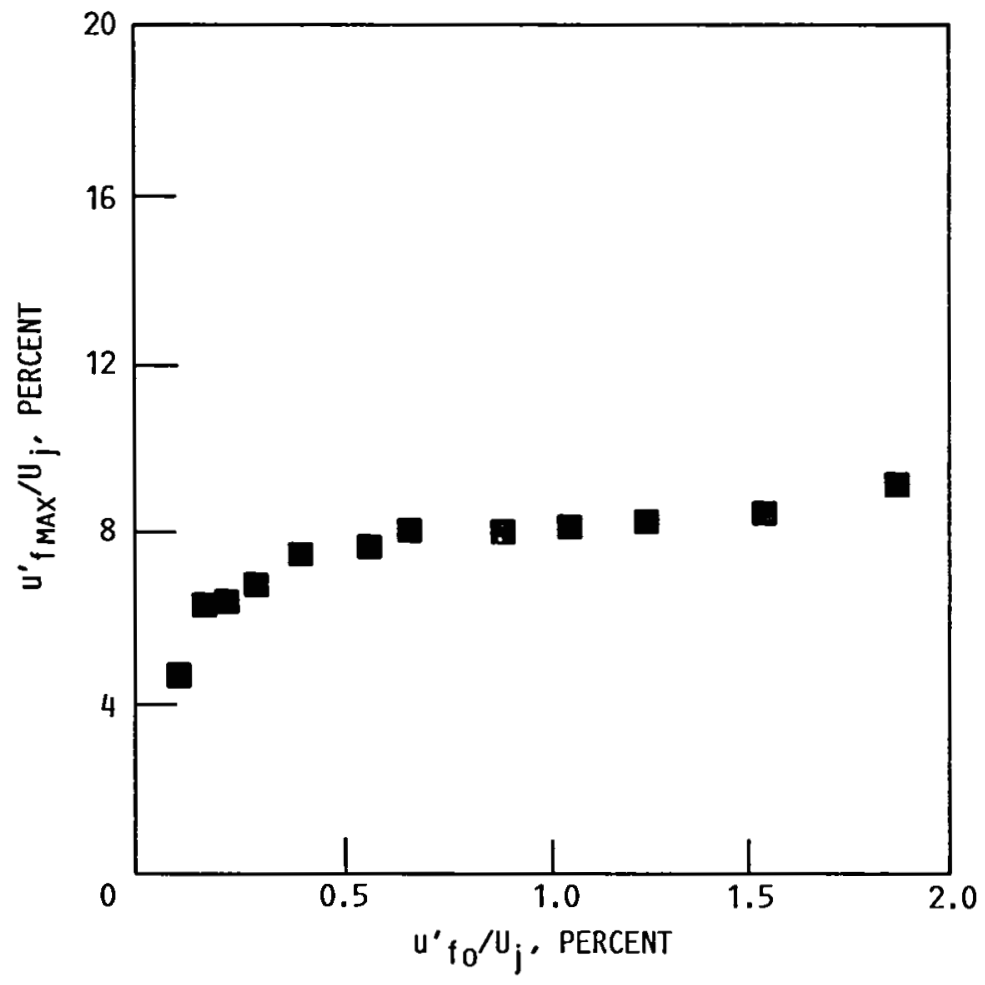

FIGURE 10. - VARIATION OF THE PEAK LEVEL ATTAINED BY THE FUNDAMENTAL WAVE WITH THE INITIAL LEVEL OF EXCITATION, $(\mathrm{St}=0.5, \mathrm{M}=0.2)$. 

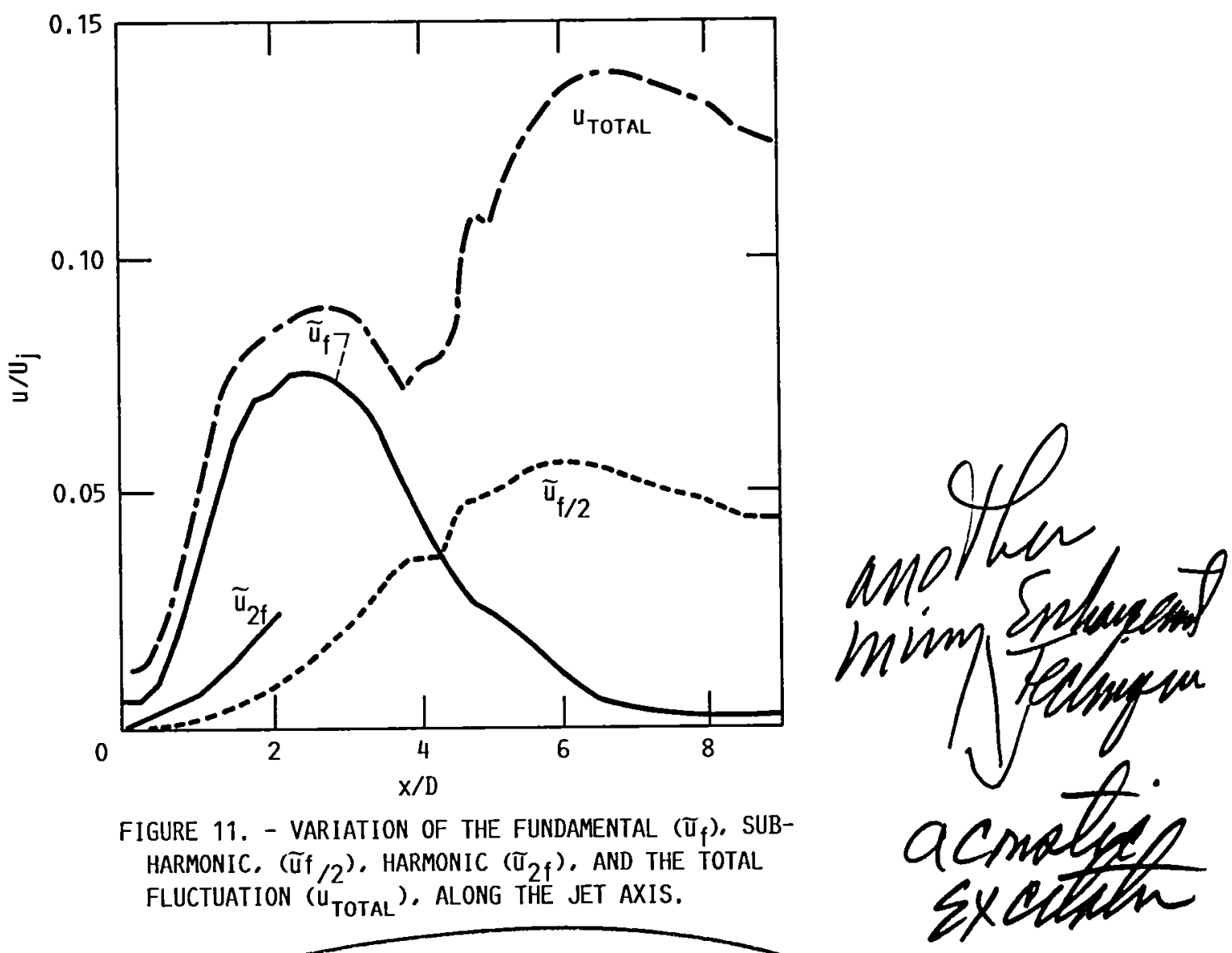

FIGURE 11. - VARIATION OF THE FUNDAMENTAL $\left(\widetilde{U}_{f}\right)$, SUBHARMONIC, ( $\widetilde{f} f / 2)$, HARMONIC $\left(\widetilde{U}_{2 f}\right)$, AND THE TOTAL FLUCTUATION (U TOTAL), ALONG THE JET AXIS.

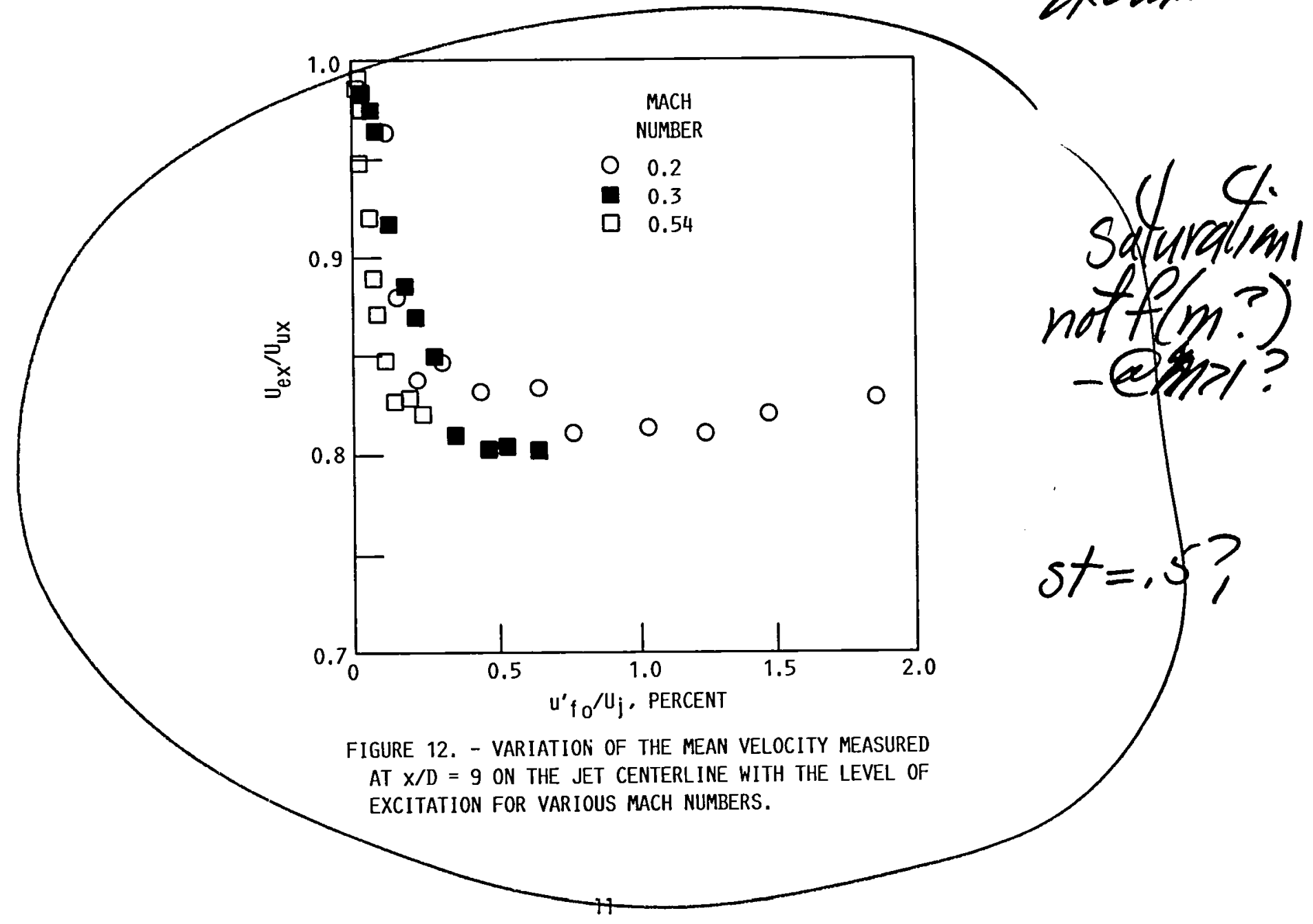




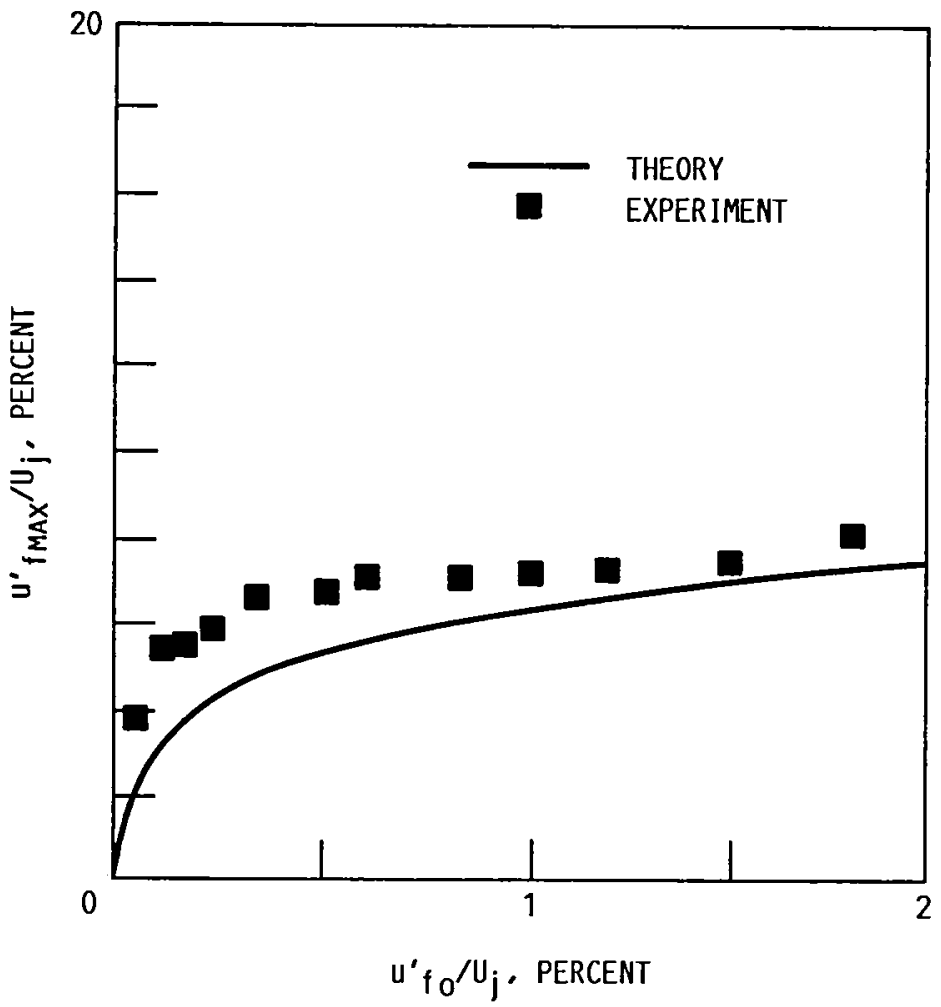

FIGURE 13. - COMPARISON OF EXPERIMENT VERSUS THEORY FOR THE VARIATION OF THE PEAK LEVEL ATTAINED BY THE FUNDAMENTAL WITH THE INITIAL LEVEL OF EXCITATION, $(S t=0.5, M=0.2)$.

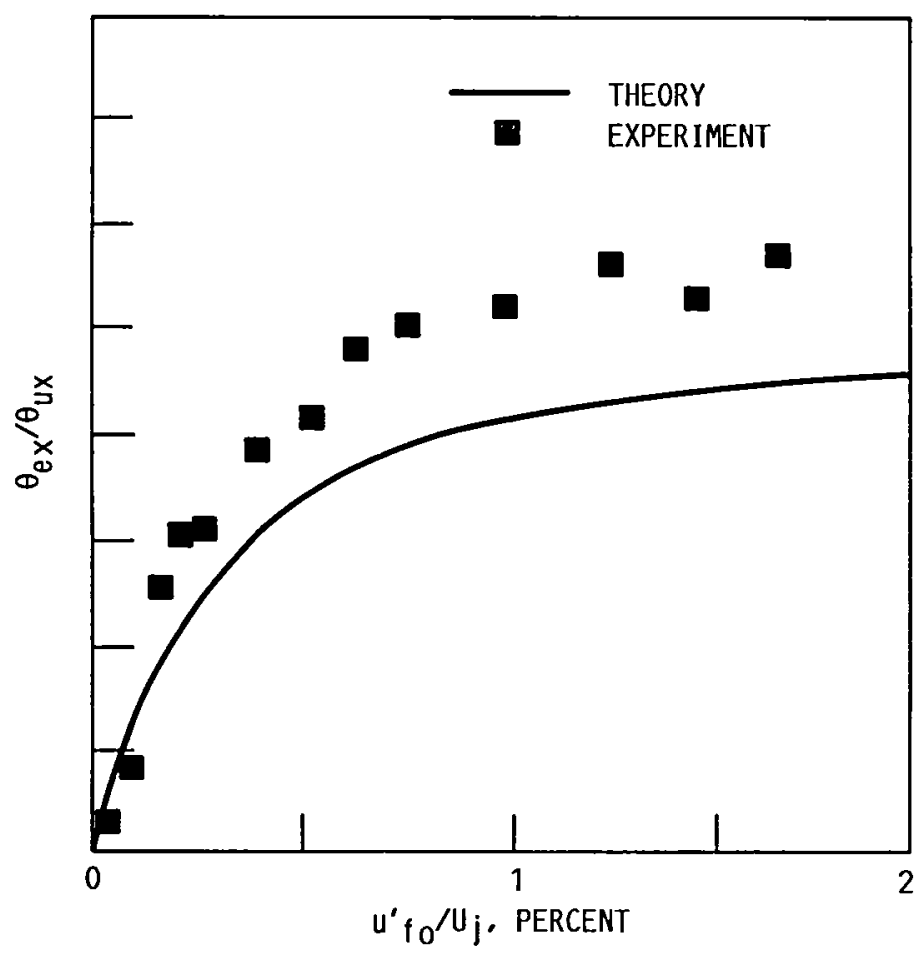

FIGURE 14. - COMPARISON OF EXPERIMENT VERSUS THEORY FOR THE VARIATION OF MOMENTUM THICKNESS AT $X / D=9$ WITH THE INITIAL LEVEL OF EXCITATION, $(S t=0.5$. $M=0.2$ ). 


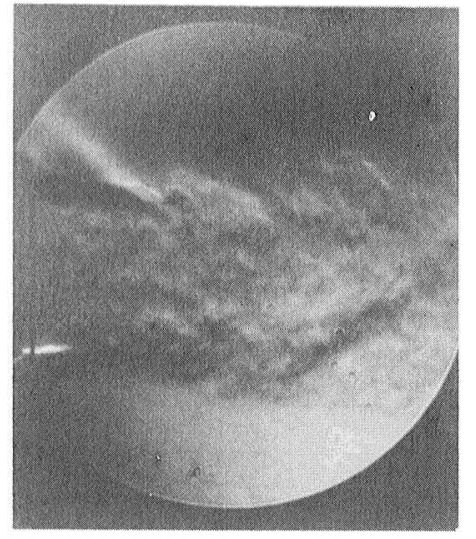

(A) NO EXCITATION.

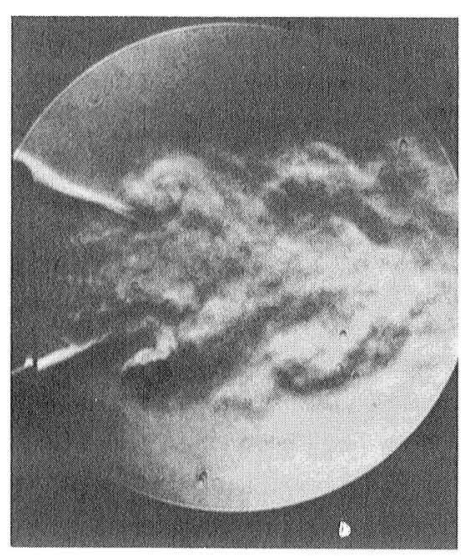

(C) $10 \mathrm{~V}$

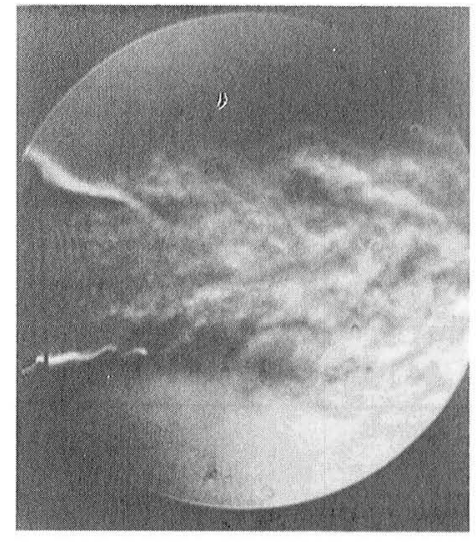

(B) $1 \mathrm{~V}$.

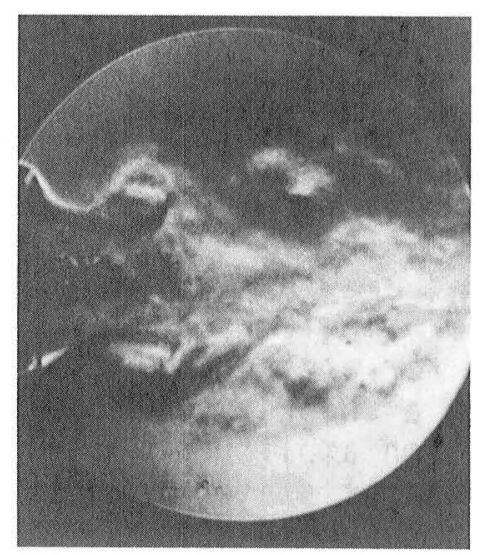

(D) $40 \mathrm{~V}$.

FIGURE 15. - SCHLIEREN PHOTOGRAPHS OF JETS AT VARIOUS LEVELS OF EXCITATION (FROM REF. 3). 


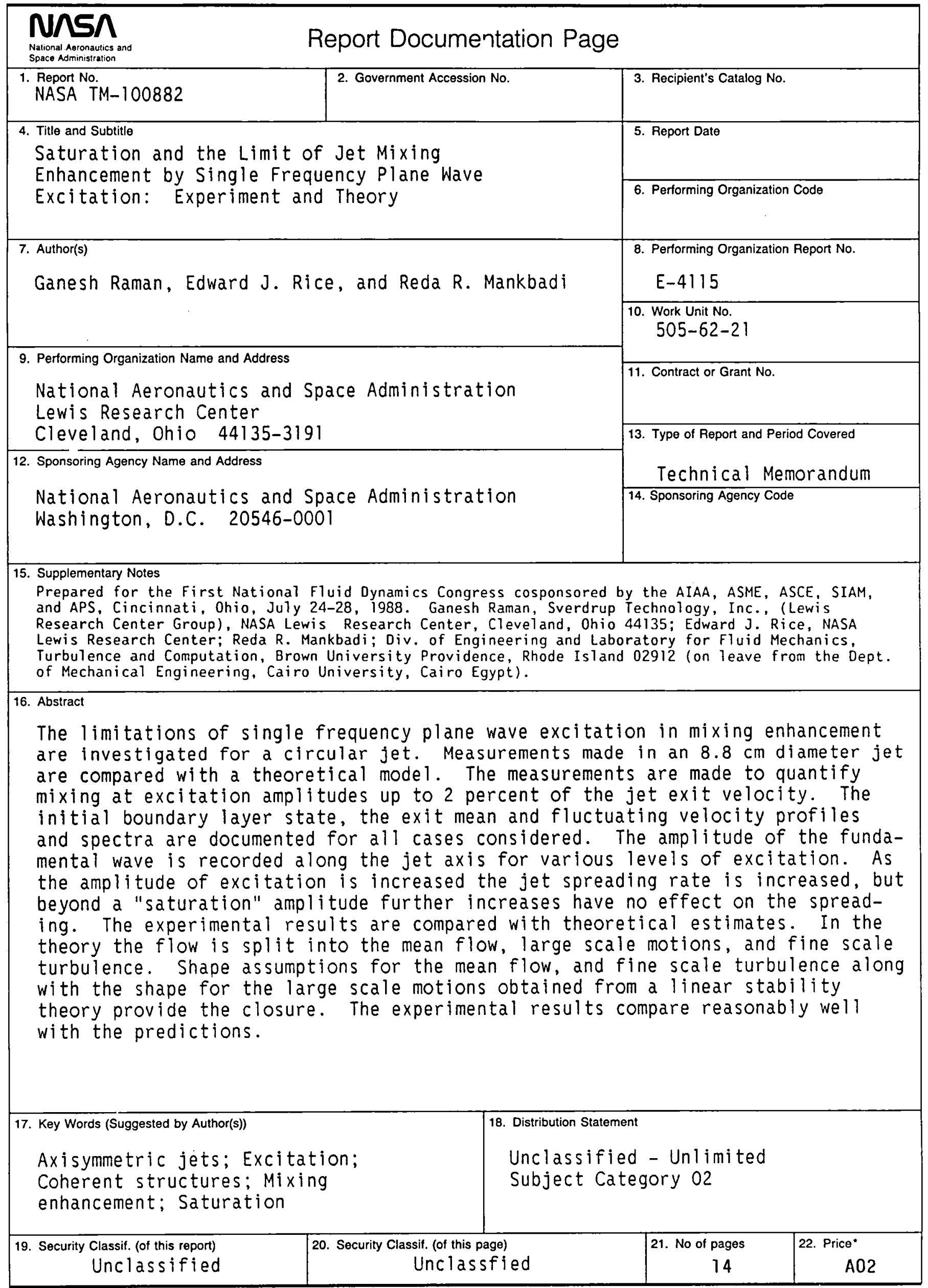


National Aeronautics and

Space Administration

Lewis Research Center

Cleveland, Ohio 44135

Oricial Business

Penalty for Pitvate Use $\$ 300$

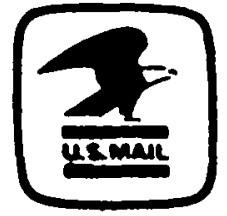

Postage and Fees Paid National Aeronautics and Space Administration NASA-451 